


\title{
Education, Disappointment and Optimal Policy
}

\author{
Dan Anderberg \\ Claudia Cerrone
}

CESIFO WORKING PAPER NO. 5141

CATEGORY 1: PubliC FinANCE

DECEMBER 2014

An electronic version of the paper may be downloaded

- from the SSRN website:

- from the RePEc website:

- from the CESifo website:

WWw.SSRN.com

www.RePEc.org

www.CESifo-group.org/wp

\section{CESifo}




\title{
Education, Disappointment and Optimal Policy
}

\begin{abstract}
Justification for policies to encourage investments in education, particularly for individuals at the lower end of the ability distribution, may be provided by behavioural economics. We present a prototypical model where individuals who are potentially loss averse around their expected outcome make risky investments in education and we draw on optimal tax theory to explore the design of policy. The model highlights the critical roles played by (i) the relationship between behavioural risk preferences, standard risk aversion and labour supply behaviour, (ii) the risk properties of education, and (iii) the degree of observability of individual academic ability.
\end{abstract}

JEL-Code: D810, H210, I210.

Keywords: education, risk, disappointment, optimal taxation.

\author{
Dan Anderberg \\ Department of Economics \\ Royal Holloway, University of London \\ United Kingdom - TW20 0EX Surrey \\ dan.anderberg@rhul.ac.uk
}

\author{
Claudia Cerrone \\ Department of Economics \\ Royal Holloway, University of London \\ United Kingdom - TW20 0EX Surrey \\ claudia.cerrone.2011@rhul.ac.uk
}

December 4, 2014

We would like to thank Pedro Bordalo, Dan Hamermesh, Henrik Kleven, Philip Neary, and seminar participants at the meetings of the European Economic Association, the Association for Public Economic Theory, the Spring Meeting of Young Economists, the workshop on Risk Preferences and Decisions under Uncertainty at Humbolt University, the Uppsala Centre for Fiscal Studies, and Royal Holloway for helpful comments. 


\section{INTRODUCTION}

Education policy is pervasive around the world, uniformly encouraging youth to investments in schooling. This is particularly true at the lower end of the distribution of educational outcomes with numerous policy initiatives designed to ensure that youth do not drop out of education too soon. The most obvious form is school-leaving age policies: in 2012, President Barack Obama in his State of the Union Address, called for every state to require students to stay in school until they turn 18 or until they graduate from High School and, in the UK, from summer 2015 youth will be required to stay in education until age 18. Other examples include large scale subsidy programmes for post-compulsory education, e.g. the Education Maintenance Allowance which operated throughout the UK between 2002 and 2010 .

Such initiatives are motivated by research demonstrating the long-term consequences of leaving education early, both in terms of future earnings and in terms of other nonpecuniary dimensions (Oreopoulos and Salvanes, 2011). Indeed, the literature generally finds relatively high rates of return on education (Card, 2001), which some observers interpret as evidence of some form of market failure. The most obvious case would be that financial constraints prevent some youth from staying in school longer (Kane, 2001). However, Carneiro and Heckman (2002) show that low college participation among the disadvantaged in US cannot be explained by short-term credit constraints 1

Another possibility is that the "failure" lies not with the market, but rather with the individuals' choices being driven by non-standard or "behavioural" preferences (Lavecchia et al., 2014). Given that education choices are heavily influenced by time- and risk preferences which are both focal areas for behavioural research, there has been surprisingly few attempts at integrating behavioural economic theories into the research on education. Moreover, from a cursory glance it is natural to expect that behavioural phenomena may justify more proactive education policies.

\footnotetext{
${ }^{1}$ Dearden et al. (2004) reach a similar conclusion for participation in post-compulsory education in the UK.
} 
Consider the notion that individuals fail to be time-consistent. One standard approach is to model persistent "present biasedness" in the form of hyperbolic discounting which is well-known to lead to underinvestment (Laibson, 1997). An alternative approach, which may be particularly relevant to investments in education, would be to model the individuals' discount rates as decreasing over adolescence (O'Donoghue and Rabin, 2001). The upshot of this would be that individuals make decisions about leaving education when their discount rates are still high compared to their long-run adult preferences. As a result they would generally leave education too soon and regret this from their own adult perspective, particularly those who leave education at a relatively younger age.

For choices under risk the most well-known non-expected utility model is prospect theory and the notion of loss aversion (Kahneman and Tversky, 1979; Kahneman, Knetsch and Thaler, 1991). As a simple illustration of the potential justification for policy, suppose that individuals, who are fundamentally risk neutral, differ in ability, $\alpha \in A$, which, combined with an education investment $z$, determines the individual's chances $\pi(z, \alpha)$ of obtaining a "high wage" $w_{H}$ versus a "low wage" $w_{L}$, where $\Delta w \equiv w_{H}-w_{L}>$ 0. Efficiency would require that everyone invests up to the point where the marginal benefit of education, $\pi_{z}^{H}(z, \alpha) \Delta w$, equals the marginal cost. However suppose that each individual has a "reference point" $\bar{w}(\alpha) \in\left(w_{L}, w_{H}\right)$, representing her aspiration level, which we assume to be increasing in ability. Due to loss aversion, there is a "kink" in the agent's utility function leading to the slope $1+\psi$ at $w<\bar{w}(\alpha)$ and a slope $1-\psi$ at $w \geq \bar{w}(\alpha) 2$ In order to induce efficient choices, the investment by an individual of ability $\alpha$ is subsidised at rate $\varsigma(\alpha)$. It can easily be shown that the efficiency-restoring subsidy is positive for all individuals with low reference points and negative for all individuals with high reference points: $\varsigma(\alpha) \geq 0$ if and only if $\bar{w}(\alpha) \leq \frac{1}{2}\left(w_{H}+w_{L}\right) \cdot 3$ The intuition is simple: low ability/aspiration individuals who, due to loss aversion, downplay gains

\footnotetext{
${ }^{2}$ The assumption of linear slopes is for simplicity. A more general setup is presented by Lecouteux and Moulin (2014).

${ }^{3}$ The subsidy rate required to induce efficient choices can be shown to equal $\varsigma(\alpha)=$ $(2 \psi / \Delta w)\left[\left(w_{H}+w_{L}\right) / 2-\bar{w}(\alpha)\right]$. Note that $\varsigma(\alpha)=0$ when $\psi=0$ : if the agents are not loss averse, they should face the true marginal cost.
} 
above comparatively low reference points need to have their incentives for educational investments boosted. This is not the case for high ability/aspiration agents whose aversion to losses relative to comparatively high reference points is already motivating them to invest beyond the efficient level.

This simple model, while insightful, however ignores four key dimensions. First, it ignores basic risk aversion and labour supply. Indeed, there is ample evidence that individuals are averse to risk when making educational choices. For instance, Skyt-Nielsen and Vissing-Jorgensen (2010) use Danish data to estimate risk aversion from observed education choices and find evidence of substantial relative risk aversion with point estimates above four 4 They did not however model labour supply. When simultaneously modelling education and labour supply choices in an expected utility framework, the same utility curvature parameter which characterizes risk attitudes also influences labour supply behaviour. This insight was used by Chetty (2006) to back out estimates of relative risk aversion from observed labor supply behavior: going through over a dozen of the most well-known labor supply studies, of varying techniques, he finds that the best estimate of relative risk aversion is unity (effectively, log utility), with two being an effective upper bound. We argue that a non-expected utility framework breaks the direct link between risk attitudes and labour supply behaviour. This is critical for optimal policy which seeks to both encourage education and provide earnings insurance.

Second, it assumes that the individuals' reference points are immutable. However, changes in the economic environment can be expected to also affect individuals' educational aspiration levels as e.g. shown recently by Taylor and Rampino (2014) for the case of the variation in the local unemployment rate. To reflect this, we consider endogenous reference points by following Gill and Prowse (2012), who model "disappointment aversion"through assuming that the individual's reference point is given by her expected outcome.5 We argue that this changes the nature of the problem as it implies direct ex

\footnotetext{
${ }^{4}$ See also Hartog and Diaz-Serrano (2007) and Belzil and Leonardi (2007).

${ }^{5}$ For key theoretical models of disappointment aversion, see Bell (1985), Loomes and Sugden (1986), Delquie and Cillo (2006), Koszegi and Rabin (2006, 2007)
} 
ante preferences against risk when choosing educational investment. This implies that "over" - versus "underinvestment" by the individuals is driven by the marginal impact of education on earning risk.

Third, it assumes that policy can be arbitrarily ability-related. This would clearly be problematic if ability is not perfectly observable: a policy that provides more generous subsidies to individuals who exhibit poor academic indicators could give rise to perverse incentives. A more robust policy analysis should consider the implications of ability being private information held by the individuals.

Finally, it is based on the view that loss aversion preferences do not reflect the individuals' long run well-being and hence should not enter the social objective function. The problem of defining a welfare criterion for normative analysis is generally complicated under non-standard choice models, in particular in settings where the individual's behaviour is best represented by multiple "selves" with changing preferences. Bernheim and Rangel (2005) argue that if there exist real and stable preferences, these should be used for the purpose of welfare analysis. Hence if loss aversion preferences are real and stable, then they should arguably be accounted for in the welfare criterion, thereby making the case for a "corrective" policy less obvious 6

The aim of the current paper is to provide a prototypical model of optimal policy in an environment where individuals, who are potentially disappointment averse and who vary in ability, make risky investments in education. In order to incorporate the provision of earnings insurance and informational constraints we build on optimal tax theory. We show, in part through theory and in part via a numerical example, how the distinction between risk- and disappointment aversion, as well as the potential unobservability of ability, can play a critical role for the structure of optimal education policy in particular.

While our model demonstrates how non-standard risk preferences can be built into a comprehensive analysis of optimal education policy it also conveys a more cautionary message. We argue through a simple empirical illustration that observational data on education choices is unlikely to provide reliable evidence on the exact nature of individuals'

\footnotetext{
${ }^{6}$ See also Lecouteux and Moulin (2014) for a discussion.
} 
risk preferences. Hence, in general, we conclude that the nature of optimal policy depends critically on several features for which high quality evidence is still limited: (i) the exact nature of individual's risk preferences in the context of education choice, (ii) the risk properties of education, and (ii) the potential endogeneity of individual's aspiration levels with respect to policy changes.

In addition to the aforementioned literatures, our paper also relates to the growing literature on optimal education and tax policy. Bovenberg and Jacobs (2005) showed that an optimal policy requires a marginal subsidy to education that counteracts the discouragement generated by an optimal earnings tax 7 However, while they allow for heterogeneity in ability, they do not model risk. A parallel literature focuses particularly on risk (da Costa and Maestri, 2007); Anderberg, 2009; Jacobs et al., 2012) but assumes ex ante identical individuals. This literature finds that the optimal education policy typically depends on whether a marginal increase in education increases or decreases wage risk. The current paper features both heterogeneity in ability and risky investments in education 8

The rest of the paper is structured as follows. Section 2 provides a basic empirical illustration of alternative models of individuals' risk preferences in relation education choices. Section 3 introduces the model and uses it to examine the individual's investment behaviour in laissez faire. Section 4 derives the optimal policy. Section 5 concludes.

\section{An Empirical Illustration}

In order to highlight how risk-preferences play a role in education choices we will provide a simple empirical illustration 9 To this end we will make use of a data set - the National Child Development Study (NCDS) - that has been used on numerous occasions for studying education choices, in particular since it also contains measures of academic

\footnotetext{
${ }^{7}$ See Maldonado (2008) and Jacobs and Bovenberg (2011) for generalizations.

${ }^{8}$ Findeisen and Sachs (2013) similarly consider a model with both heterogeneity and risk. However, they focus particularly on implementation and do not consider deviations from the expected utility framework.

${ }^{9}$ See Appendix A for details of the NCDS sample, the empirical approach, and estimates.
} 
ability and earnings realizations 10 Based on academic tests taken at age 11 we create a general measure of ability and partition the population into quartiles, $\alpha \in\left\{\alpha_{1}, \ldots, \alpha_{4}\right\}$. As measure of educational investment we discretize the age at which the individuals left full time education into three options, $z \in\left\{z_{0}, z_{1}, z_{2}\right\}$, defined as leaving at age 16 (the minimum school leaving age), 17-18, and 19 or higher respectively. Our final sample consists of 2,632 males.

Figure 1 highlights the relation between ability quartile $\alpha$, educational investment $z$, and log wages. Mean log wage, indicated by bars, increases monotonically in both ability and education. The line in each graph highlights the relationship between $z$ and wage risk as measured by the standard deviation of the log wage. For the two lowest ability groups, increasing education is associated with increasing risk. For the two top ability groups the relationship is inverted U-shaped. This resembles the results obtained by Chen (2008), based on US data, who finds that entering college is associated with an increase in wage risk, whereas completing a four year college degree is associated with a reduction in wage risk.

The purpose of the current basic illustration is to highlight that observed choices are consistent with individuals having fairly strong preferences against risk, but that observational data on education choices alone cannot be expected to identify the exact nature of the individuals' dislike of risk. To do this we will start from a baseline case of expected utility with unit relative risk aversion - which was Chetty's (2006) central estimate of curvature consistent with observed labour supply behaviour - and argue that this under-represents the individuals' dislike of risk when making education choices. We will then show how disappointment aversion implies additional preferences against wage risk. Finally, we will consider the alternative of higher relative risk aversion.

To conceptualise the problem, assume that the realized utility for individual $i$ of ability $\alpha_{i}$ choosing education $z_{j}$ and obtaining the wage $w$ can be written as

$$
U=u\left(w, z_{j}\right)+\psi^{k}\left[u\left(w, z_{j}\right)-E\left[u\left(w, z_{j}\right) \mid z_{j}, \alpha_{i}\right]\right],
$$

\footnotetext{
${ }^{10}$ Examples include Blundell et al. (2004) who compare different approaches to estimating returns to schooling and Dearden et al. (2004) in their analysis of credit constraints.
} 

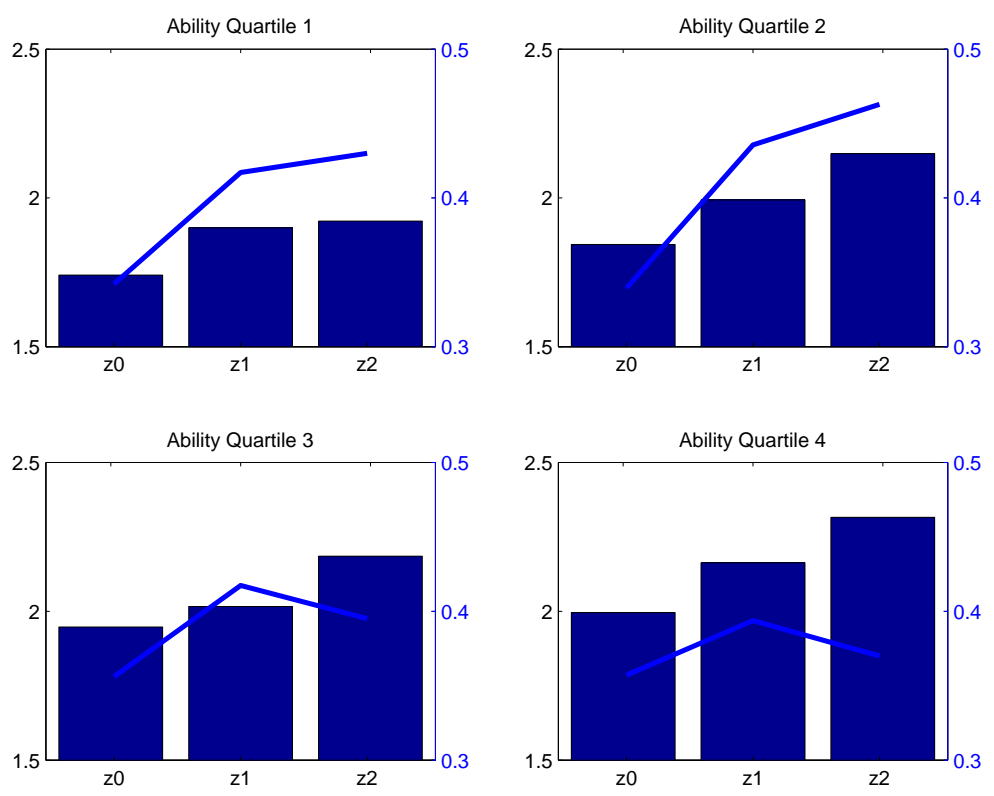

Figure 1: Mean log wage and standard deviation of log wage by ability and by educational investment

where $u\left(w, z_{j}\right)$ represents the individual's "primitive" level of well-being, and where $\psi^{k}=$ $\psi^{L}$ if the outcome is lower than its expected value and $\psi^{k}=\psi^{H}$ if it is higher, with $\psi \equiv \psi^{L}-\psi^{H} \geq 0$. Disappointment aversion is captured by the presence of the second term which draws on the formulation of Gill and Prowse (2012) by modelling the individual's realised utility as depending on the deviation from her expected outcome.

In making her education choice the individual will compare the ex ante expected value of $U$ across the available choices. Taking the expectation of (1) conditional on $\left(\alpha_{i}, z_{j}\right)$ under the assumption of log utility and a log normal conditional wage distribution yields

$$
E\left[U \mid z_{j}, \alpha_{i}\right]=E\left[\ln (w)-z_{j} \ln (1+r) \mid \alpha_{i}, z_{j}\right]-\psi \cdot \operatorname{StDev}\left[\ln (w) \mid \alpha_{i}, z_{j}\right]
$$

where the $z_{j} \ln (1+r)$ term takes into account the foregone earnings while in education 11 If the individual was a standard expected utility maximizer with unit relative risk aversion, then her preferences would be adequately captured by the first term in (2). Disappoint-

\footnotetext{
${ }^{11} \mathrm{~A}$ further constant multiplies the second term but is ignored here for expository reasons. See Appendix A for an exact derivation of (2). The constant is included in the regressions presented in the Appendix.
} 

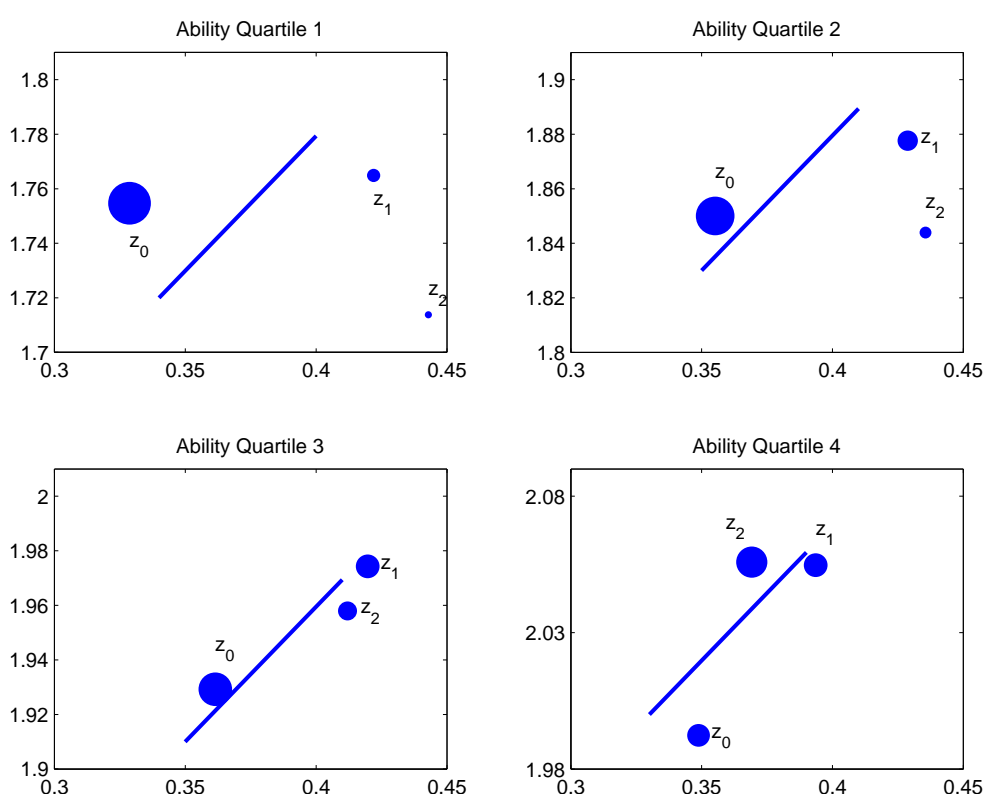

Figure 2: Risk properties of education option and frequency of choice

ment aversion $(\psi>0)$ thus induces additional preferences against variation in the log wage.

Figure 2 illustrates the terms in (2) for each cell. In particular, the horizontal axis plots the conditional standard deviation of the log wage while the vertical axis plots the conditional mean log wage after accounting for forgone earnings 12 Each circle thus corresponds to an available education choice, and its size indicates the relative frequency of that choice.

If preferences were adequately captured by standard expected utility maximization with log utility, then the vertical axis would measure the individuals' expected lifetime utility. The figure however reveals that the majority of individuals in ability groups 13 left education at the minimum school leaving age $\left(z_{0}\right)$ even though this did not offer the highest expected lifetime log utility. Disappointment aversion, $\psi>0$, would imply residual preferences against earnings variation as measured by the standard deviation, with individuals thus preferring options that are located toward the northeast in each

\footnotetext{
${ }^{12}$ In implementing this formula we let $z_{0}=0, z_{1}=2$ and $z_{2}=5$ represent the (mode) number of post-compulsory schooling years within each group, and we let $r=0.05$.
} 
panel 13 If $\log$ utility is imposed, the data thus suggests that individuals have residual dislike of log wage variability when choosing education, consistent with disappointment aversion.

The obvious alternative way to rationalize the observed choices is to allow for a higher level of risk aversion, replacing the log utility with a CRRA function with risk aversion parameter $\gamma$ (and setting $\psi=0$ ). In Appendix $\mathrm{A}$ we outline how the current data can be used to estimate either (i) a model with disappointment aversion $\psi>0$ under the assumption of unit relative risk aversion $(\gamma=1)$, or (ii) a model with relative risk aversion $\gamma>1$ under the assumption of no disappointment aversion $(\psi=0)$. In the first case we obtain strongly positive estimates of $\psi$, around 0.6. Conversely, in the second case, we obtain estimates of $\gamma$ which are well above unity, around 4 , thus similar in magnitude to Skyt-Nielsen and Vissing-Jorgensen (2010).

While there is no formal equivalence between the models - and, in the current case, the model with disappointment aversion fits the data slightly better than the pure risk aversion model - in practice, they are nearly observationally equivalent from the perspective of education choice data.14 Hence empirically disentangling individuals' risk preferences in the context of education choices will require more tailored experimental research designs than offered by observational data on education choices.

In the next section we will introduce a theoretical model which we will then proceed to simulate numerically with the aim of illustrating how the structure of optimal policy depends critically on the nature of the individuals' risk preferences and on the potential unobservability of their abilities.

\section{MODEL}

This section sets up the theoretical model of risky investments in education that will be used for the analysis of optimal policy.

\footnotetext{
${ }^{13}$ The slope of the "indifference curves" highlighted in the figure are given by the basic estimate of $\psi$ in row one, column (iii) of Table 1 in Appendix A.

${ }^{14}$ Observed and simulated choice frequencies are presented in Table 2 in Appendix A.
} 


\subsection{Model Set-up}

An individual's economically active life consists of two periods or "phases". The first period is a youth-phase. An individual devotes a fraction $z \in[0,1]$ of this phase to acquiring education 15 The cost of education is given by foregone earnings, and the youth wage is denoted by $w_{0}>0$. For simplicity, we assume that all consumption occurs in adulthood. Hence an individual's earnings in youth are carried forward to adulthood in the form of savings,

$$
s(z) \equiv(1-z) w_{0}
$$

The second period is an adult-phase during which the individual works and consumes. Preferences are additively separable over consumption and leisure, $u(c)+\nu(1-l)$, where $u(\cdot)$ and $\nu(\cdot)$ are strictly increasing, strictly concave and twice differentiable.

Upon completing education and entering adulthood, the individual will obtain one of two potential wages $\left\{w_{L}, w_{H}\right\}$, where $w_{H}>w_{L} \geq w_{0}$. The probability of wage $w_{j}$, denoted $\pi^{j}(z, \alpha) \equiv \operatorname{Pr}\left(w_{j} \mid \alpha, z\right)$, depends on the individual's investment $z$ and on her academic ability, $\alpha$. Ability is distributed according to a probability density function $f(\alpha)$ on a discrete set $A=\left\{\alpha_{1}, \ldots, \alpha_{N}\right\}$. Ability and education are assumed to be complements in raising the probability of a high wage outcome:

Assumption 1. $\pi_{z}^{H}(z, \alpha)>0, \pi_{z z}^{H}(z, \alpha)<0, \pi_{\alpha}^{H}(z, \alpha)>0$ and $\pi_{z \alpha}^{H}(z, \alpha)>0$ for all $\alpha$ and $z$.

The timing is as follows. The individual learns her ability and chooses a level of education $z$. Upon entering adulthood, her wage realization is revealed and she then chooses labour supply and consumption. Savings $s$ carried forward increase adult consumption by $r s(z)$, where $r \in(0,1)$, reflecting that adulthood is longer than youth.

3.1.1. Disappointment Aversion Consider an individual with ability $\alpha$ who has made the investment $z$. Let $v\left(w_{j}, r s(z)\right)$ denote the individual's indirect utility from consumption and leisure at the wage $w_{j}$ and let $\bar{v}$ denote the expected value of this indirect utility,

\footnotetext{
${ }^{15}$ Hence education is now modelled as a choice from a continuous interval.
} 
$\bar{v}(z, r s ; \alpha) \equiv \sum_{j=L, H} \pi^{j}(z, \alpha) v\left(w_{j}, r s(z)\right)$. Using the shorthand $v_{L}$ and $v_{H}$ for the indirect utility at the low- and the high wage respectively and modelling disappointment aversion as in (11), the individual's realized utility in the "low wage" and the "high wage" state would be $v_{L}+\psi^{L}\left(v_{L}-\bar{v}\right)$ and $v_{H}+\psi^{H}\left(v_{H}-\bar{v}\right)$ respectively. Taking the expectation over the wage realization yields that the individual's ex ante utility can be written as

$$
\sum_{j=L, H} \pi^{j}(z, \alpha) v_{j}-\psi \sigma(z, \alpha)\left(v_{H}-v_{L}\right)
$$

where, as before, $\psi \equiv \psi^{L}-\psi^{H} \geq 0$ and where

$$
\sigma(z, \alpha) \equiv \pi^{L}(z, \alpha) \pi^{H}(z, \alpha)
$$

For any $\alpha, \sigma(z, \alpha)$ is an increasing function of $z$ up to the point where $\pi^{H}(z, \alpha)=1 / 2$ and decreasing in $z$ thereafter. Note also that with two potential wages, the wage variance is proportional to $\sigma(z, \alpha)$. Hence the model features an inverted $\mathrm{U}$-shaped relation between $z$ and wage risk at the individual level, although for low ability agents wage risk will be monotonically increasing in education in so far as for them $\pi^{H}(z, \alpha)<1 / 2$ for any available $z$.

\subsection{Laissez Faire}

In the absence of any policy the individual's adult maximized utility at wage $w_{j}$ is $v\left(w_{j}, r s\right) \equiv \max _{l}\left\{u\left(w_{j} l+r s\right)+\nu(1-l)\right\}$, with associated labour supply and consumption $l\left(w_{j}, r s\right)$ and $c\left(w_{j}, r s\right)$. In youth the individual chooses $z$ to maximize (4). Assumption 1 naturally implies ability-monotonicity of the investment. Simple comparative statics show that the laissez-faire equilibrium investment, denoted $z^{*}\left(\alpha_{k}\right)$, increases in the individual's ability, $\alpha_{k}$. It follows that the equilibrium success probability, $\pi^{H}\left(z\left(\alpha_{k}\right), \alpha_{k}\right)$, increases in $\alpha_{k}$. For the purpose of highlighting the ability gradient in the laissez-faire equilibrium, we assume that the equilibrium high wage probability effectively spans the entire unit interval.

Assumption 2. In the laissez-faire equilibrium $\pi^{H}\left(z^{*}\left(\alpha_{1}\right), \alpha_{1}\right)$ and $\pi^{L}\left(z^{*}\left(\alpha_{N}\right), \alpha_{N}\right)$ are negligibly small. 
We define the rate of return on education in standard fashion as,

$$
\rho \equiv \frac{\pi_{z}^{H}\left(w_{H}-w_{L}\right) E[l]}{w_{0}}
$$

where $E[l]$ denotes the expected labour supply.

The individual is effectively choosing between two alternative investments: education and savings, where one investment option is risky and one is safe, causing a deviation between $\rho$ and $r$. As shown by Levhari and Weiss (1974), $\rho$ will exceed $r$ if, for the individual, a marginal increase in education increases wage risk. In the current model, low (high) ability agents will have an equilibrium probability of a high wage which is less than (exceeds) a half, implying that a marginal increase in education is associated with a marginal increase (decrease) in wage risk. The Levhari and Weiss result thus suggests that $\rho>r$ for lower ability individuals and $\rho<r$ for higher ability individuals. As our model also includes endogenous labour supply, we demonstrate that this holds particularly at the lower and upper end of the ability distribution.

Proposition 1. In laissez-faire, in the absence of disappointment aversion, $\rho^{*}\left(\alpha_{1}\right)>r$ while $\rho^{*}\left(\alpha_{N}\right)<r$.

As shown above, under disappointment aversion, the individuals have direct preferences against wage risk (captured by the $\sigma(z, \alpha)$ term in (4) and, more generally, by the standard deviation term in (2) $)$. Hence we would expect that the introduction of disappointment aversion into the individuals' preferences will enhance the Levhari and Weiss effect as the individuals will adjust their educational investments further in order to reduce wage risk, with lower ability individuals reducing their investments and higher ability individual increasing their investments. The following result verifies that this indeed holds at the tails of the ability distribution.

Proposition 2. Disappointment aversion induces agents at the lower (upper) tail of the ability distribution to reduce (increase) their investments in education: $\partial z^{*}\left(\alpha_{1}\right) / \partial \psi<0$ and $\partial z^{*}\left(\alpha_{N}\right) / \partial \psi>0$. 
Hence in line with the simple model outlined in the introduction, we obtain that low (high) ability individuals reduce (increase) their educational investments in response to loss aversion. However, with endogenous reference points given by the expected outcome, the effect is driven not by an assumed exogenous relationship between ability and reference points, but rather by the equilibrium marginal impact of education on wage risk.

\subsection{Numerical Example}

We present here a simple numerical example that will also be carried forward to illustrate optimal policy. Consider standard CES preferences,

$$
u(c)+\nu(1-l)=\phi \frac{c^{1-\gamma}}{1-\gamma}+\frac{(1-l)^{1-\gamma}}{1-\gamma} .
$$

The ability distribution is assumed to be uniform on $A=\{0.1,0.2, \ldots, 0.9\}$ and we posit the following success probability function,

$$
\pi^{H}(z, \alpha)=\alpha\left(1-e^{-\frac{\eta}{\alpha} z}\right)
$$

with curvature parameter $\eta=4$. In addition to satisfying Assumption 1 this function has the feature that, in line with Figure 1, wage risk is monotonically increasing in $z$ for low ability individuals but is inversely U-shaped for high ability individuals 16 We set $w_{0}=2$ and assume that individuals who are unsuccessful remain on the youth wage, $w_{L}=w_{0}$, whereas successful individuals double their wage, $w_{H}=4$, and set $r=0.05$. As we vary risk preferences we adjust the preference weight $\phi$ so as to maintain aggregate labour supply at a constant value of $\bar{l}=0.75$ in the laissez-faire allocation.

We use $\log$ utility, $\gamma=1$, and no disappointment aversion, $\psi=0$, as our "baseline" specification.17 When considering the impact of risk preferences we draw on Section 2

\footnotetext{
${ }^{16}$ For ability types at the lower end of the ability distribution, $\pi^{H}(z, \alpha)<1 / 2$ for all $z \in[0,1]$ implying that $\sigma(z, \alpha)$ will be strictly increasing in $z$ at any $z \in[0,1]$. In contrast, higher types will achieve $\pi^{H}(z, \alpha) \geq 1 / 2$ for sufficiently large investments.

${ }^{17}$ At this specification, the lowest ability type spends less than ten percent of their youth phase in education and obtain a high wage with less than ten percent probability. The highest ability type spends nearly their entire youth phase - 97 percent - and obtain a high wage with close to 90 percent probability.
} 
and consider values of $\psi$ up to 0.65 and values of $\gamma$ up to 3.5. Figure 3 shows how the rate of return to education is affected by the introduction of disappointment aversion (left panel) and varying levels of risk aversion (right panel). Either form of dislike of risk, combined with the assumed pattern for the marginal impact of education on wage risk, generates a rate of return on education which is substantially increased relative to the baseline specification for low ability individuals and somewhat reduced for high ability individuals.
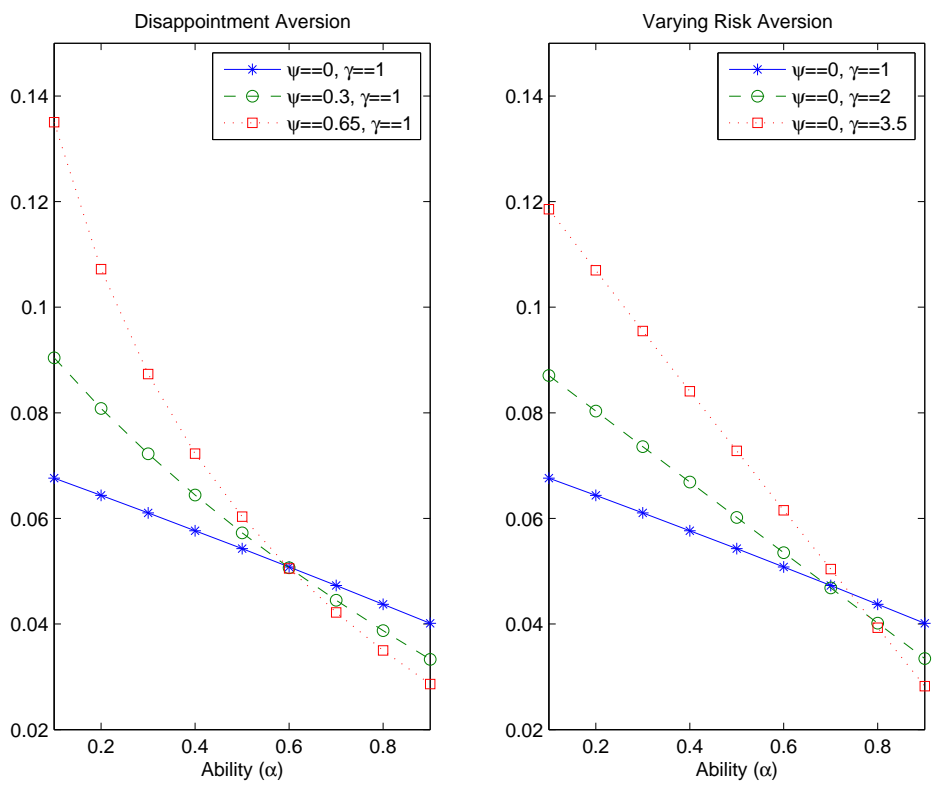

Figure 3: Rate of return on education under different levels of disappointment aversion (left panel) and risk aversion (right panel)

\section{Optimal Allocation and Policy}

There are two related justifications for policy in the current environment. First, the individuals dislike earning risk motivates some form of publicly provided earnings insurance. Second, an intervention may be required to adjust the agents' investment incentives. The standard approach to modelling government provision of earnings insurance is in the form of a redistributive income tax-transfer system (Mirrlees, 1971; Brewer et al., 2010) We will combine this with a policy instrument for adjusting investment incentives. This could 
be in the form of an education subsidy. However, in the current model, as the individuals are choosing between investing in savings or in education, a tax on savings can equally be used as policy instrument. Since the latter is conceptually easier to incorporate in the model we use this as policy instrument.

Following the standard approach in the optimal tax literature since Stiglitz (1982) we first characterize the socially optimal allocation subject to truthful revelation of private information and then back out the implied optimal "wedges" structure 18 We consider two alternative information scenarios:

Scenario 1: "Observable Ability". Individuals' abilities are observable, but their wage realizations are private information.

Scenario 2: "Unobservable Ability". Individuals' abilities and wage realizations are both private information.

In scenario 2 we assume that individuals can only "understate" their abilities. This scenario thus allows us to check on the potential the issue of perverse incentives for the individuals to mask their true academic ability.

\subsection{The Constrained Social Optimum}

4.1.1. Social Objective and Incentive Constraints The social planner is assumed to maximize the ex ante utility for a representative individual who is yet to learn her ability. We view disappointment aversion as representing "true and stable" components of the individuals' preference and thus account for these preferences in the social objective function. The planner's problem is hence to choose an allocation $\left\{c\left(\alpha_{k}, w_{j}\right), y\left(\alpha_{k}, w_{j}\right), z\left(\alpha_{k}\right)\right\}_{k=1, \ldots, N}^{j=L, H}$ so as to maximize

$$
\sum_{\alpha_{k} \in A} f\left(\alpha_{k}\right)\left\{\sum_{j=L, H} \pi^{j}\left(z\left(\alpha_{k}\right), \alpha_{k}\right) v\left(\alpha_{k}, w_{j}\right)-\psi \sigma\left(z\left(\alpha_{k}\right), \alpha_{k}\right)\left[v\left(\alpha_{k}, w_{H}\right)-v\left(\alpha_{k}, w_{L}\right)\right]\right\}
$$

\footnotetext{
${ }^{18}$ In doing so we will focus on the structure of optimal marginal incentives, not on "implementation" (Findeisen and Sachs, 2013).
} 
where (somewhat abusing the notation)

$$
v\left(\alpha_{k}, w_{j}\right) \equiv u\left(c\left(\alpha_{k}, w_{j}\right)\right)+\nu\left(1-\frac{y\left(\alpha_{k}, w_{j}\right)}{w_{j}}\right),
$$

is the "primitive" utility obtained by an individual of type $\alpha_{k}$ at the wage realization $w_{j}$. There is a resource constraint which can be written as $\sum_{\alpha_{k} \in A} f\left(\alpha_{k}\right) R\left(\alpha_{k}\right) \geq 0$, where

$$
R\left(\alpha_{k}\right) \equiv r w_{0}\left(1-z\left(\alpha_{k}\right)\right)+\sum_{j=L, H} \pi^{j}\left(z\left(\alpha_{k}\right), \alpha_{k}\right)\left(y\left(\alpha_{k}, w_{j}\right)-c\left(\alpha_{k}, w_{j}\right)\right) .
$$

Turning to the incentive constraints, as an individual's wage is private information, we impose $N$ wage-reporting constraints

$$
v\left(\alpha_{k}, w_{H}\right) \geq \widehat{v}\left(\alpha_{k}, w_{H}\right) \text { for all } a_{k} \in A
$$

where $\widehat{v}\left(\alpha_{k}, w_{H}\right)$ is the utility of a type $\alpha_{k}$ agent who falsely reports a low wage. When ability is private information, we also impose the following ability reporting constraints: for all $\alpha_{k}, \alpha_{k^{\prime}} \in A$,

$$
\begin{gathered}
\sum_{j=L, H} \pi^{j}\left(z\left(\alpha_{k}\right), \alpha_{k}\right) v\left(\alpha_{k}, w_{j}\right)-\psi \sigma\left(z\left(\alpha_{k}\right), \alpha_{k}\right)\left\{v\left(\alpha_{k}, w_{H}\right)-v\left(\alpha_{k}, w_{L}\right)\right\} \geq \\
\sum_{j=L, H} \pi^{j}\left(z\left(\alpha_{k^{\prime}}\right), \alpha_{k}\right) v\left(\alpha_{k^{\prime}}, w_{j}\right)-\psi \sigma\left(z\left(\alpha_{k^{\prime}}\right), \alpha_{k}\right)\left\{v\left(\alpha_{k^{\prime}}, w_{H}\right)-v\left(\alpha_{k^{\prime}}, w_{L}\right)\right\}
\end{gathered}
$$

An allocation is said to be "incentive compatible" if no agent can achieve a higher expected utility by misreporting either her ability (when unobservable) and/or her wage realization. Indeed, the above constraints are sufficient to ensure incentive compatibility. To see this, note that any type who truthfully reports her ability will by (12) also have the incentive to truthfully report her subsequent wage realization. Slightly less obvious is the fact that no individual has any incentive to "double deviate" (Kocherlakota, 2010) involving first misreporting her ability and then also misreporting the wage realization. However, note that any agent $\alpha_{k}$ who has reported being of type $\alpha_{k^{\prime}}$ will have the same wage reporting incentives as a true $\alpha_{k^{\prime}}$-type agent: the fact that they had different success probabilities will not be relevant for wage reporting incentives once the wages have been realized 19

\footnotetext{
${ }^{19} \mathrm{~A}$ formal proof of incentive compatibility uses the notion of a "reporting strategy" (Kocherlakota, 2006) and is available on request.
} 
For reference, the first order conditions associated with the socially optimal allocation are given in Appendix B.

4.1.2. Implicit Wedges In order to characterize policy we define some key wedges representing the implicit marginal tax rate on earnings and the marginal tax on savings which represent the investment policy tool. Hence let $T(\cdot)$ denote an earnings tax and let $S(\cdot)$ denote a tax on savings. The implicit definition of the marginal tax on earnings is familiar from the optimal tax literature: for ability type $\alpha_{k}$ at the wage realization $w_{j}$ we define

$$
T^{\prime}\left(\alpha_{k}, w_{j}\right) \equiv 1-\nu^{\prime}\left(1-\frac{y\left(\alpha_{k}, w_{j}\right)}{w_{j}}\right) \frac{1}{w_{j}} \frac{1}{u^{\prime}\left(c\left(\alpha_{k}, w_{j}\right)\right)} .
$$

Based on the individual's ex ante choice of $z$ under a general policy $\{T(\cdot), S(\cdot)\}$ the corresponding natural implicit marginal investment wedge for type $\alpha_{k}$ is

$$
S^{\prime}\left(\alpha_{k}\right) \equiv 1-\frac{\left\{\pi_{z}^{H}\left(z\left(\alpha_{k}\right), \alpha_{k}\right)-\psi \sigma_{z}\left(z\left(\alpha_{k}\right), \alpha_{k}\right)\right\} \Delta v\left(\alpha_{k}\right)}{r w_{0}\left\{\sum_{j} \pi^{j}\left(z\left(\alpha_{k}\right), \alpha_{k}\right) u^{\prime}\left(c\left(\alpha_{k}, w_{j}\right)\right)-\psi \sigma\left(z\left(\alpha_{k}\right), \alpha_{k}\right) \Delta u^{\prime}\left(c\left(\alpha_{k}\right)\right)\right\}} .
$$

In the current environment, a marginal increase in education does not lead to a marginal increase in the individual's wage as in Bovenberg and Jacobs (2005), but rather to a marginal increase in the probability of a high wage realization. In considering the private benefit of increasing education, the individual will hence consider not the marginal tax on earnings, but rather the increase in the tax on earnings associated with going from a low to a high wage. To this end we also define the "implicit effective marginal tax rate" for ability type $\alpha_{k}$ as

$$
T_{\Delta}^{\prime}\left(\alpha_{k}\right) \equiv \frac{\Delta T\left(\alpha_{k}\right)}{\Delta w E\left[l\left(\alpha_{k}\right)\right]},
$$

where $\Delta T\left(\alpha_{k}\right) \equiv \Delta y\left(\alpha_{k}\right)-\Delta c\left(\alpha_{k}\right)$.

\subsection{Analysis of the Optimal Allocation}

In analysing the optimal allocation, we let $\lambda, \mu\left(\alpha_{k}\right)$ and $\chi\left(\alpha_{k}, \alpha_{k^{\prime}}\right)$ denote the multipliers on the resource constraint and on the incentive constraints (12) and (13) respectively. Note that all $\chi\left(\alpha_{k}, \alpha_{k^{\prime}}\right)$ multipliers are zero when ability is observable. 
4.2.1. The Social Value of Resources A key aspect of the optimum is the relationship between the social value of resources $\lambda$ and the agents' marginal utilities of consumption. Hence consider how $\lambda$ compares with the private value of resources carried forward from youth into adulthood. By combining (A10) and (A11), we obtain that

$\lambda\left[1+\sum_{k^{\prime}} \chi\left(\alpha_{k}, \alpha_{k^{\prime}}\right)-\sum_{k^{\prime}} \frac{f\left(\alpha_{k^{\prime}}\right)}{f\left(\alpha_{k}\right)} \chi\left(\alpha_{k^{\prime}}, \alpha_{k}\right)\right]^{-1}=\left[\frac{\pi^{H}\left(z\left(\alpha_{k}\right), \alpha_{k}\right)}{u^{\prime}\left(c\left(\alpha_{k}, w_{H}\right)\right)}+\frac{\pi^{L}\left(z\left(\alpha_{k}\right), \alpha_{k}\right)}{u^{\prime}\left(c\left(\alpha_{k}, w_{L}\right)\right)}\right]^{-1}$

Note that the right hand side of (17) is the harmonic mean marginal utility of consumption for ability type $\alpha_{k}$. In Scenario 1, the left hand side of (17) is simply $\lambda$, implying that the harmonic mean marginal utility of consumption is equalized across ability types. In this case the current model is effectively a "tagging" model in the tradition of Akerlof (1978), where categorial information is used in order to target groups with more need. The harmonic mean - which is lower than the arithmetic mean - features here since any additional resources provided to a given ability type has to be distributed in such a way that the wage reporting constraint remains satisfied (Kocherlakota, 2006). Why does disappointment aversion not feature in (17)? The fact that additional resources provided to a given ability type must be distributed so as to keep the wage reporting constraint satisfied means that the utility gap between the low and the high wage outcome is unaffected. Hence so is the expected welfare loss from disappointment.

When ability is private information (Scenario 2) the harmonic mean marginal utility is no longer equalized across ability types. Instead, as (17) reveals, type $\alpha_{k}$ will have a harmonic mean marginal utility of consumption that is lower than $\lambda$ if and only if type $\alpha_{k}$ is "more tempted" to mimic other types than other types are tempted to mimic type $\alpha_{k}$.

In the numerical example we find that downward adjacent ability reporting constraints are always binding when ability is private information and that, as a result, the harmonic mean marginal utility of consumption is monotonically decreasing in ability at the social optimum. This suggest that the need to avoid perverse incentives constrains optimal policy and requires a more generous policy towards higher ability individuals. 
4.2.2. Optimal Distortions The standard results of "no-distortion-at-the-top" and a positive marginal tax on earnings on low wage individuals apply to our setting, with and without disappointment aversion, and with and without observable ability.20

Proposition 3. At the social optimum, $T^{\prime}\left(\alpha_{k}, w_{L}\right)>0$ and $T^{\prime}\left(\alpha_{k}, w_{H}\right)=0$ for all $\alpha_{k} \in A$.

Of greater interest for our purposes is the optimal investment wedge. From (A14) and using the definitions in (6),$(15)$ and (16) we can derive the following result:

Proposition 4. At the social optimum, for ability type $\alpha_{k} \in A$,

$$
S^{\prime}\left(\alpha_{k}\right)=1-\frac{\lambda}{\kappa\left(\alpha_{k}\right)} \frac{1}{\left[1+H\left(\alpha_{k}\right) / f\left(\alpha_{k}\right)\right]}\left\{1-\frac{\rho\left(\alpha_{k}\right)}{r} T_{\Delta}^{\prime}\left(\alpha_{k}\right)\right\},
$$

where

$$
\kappa\left(\alpha_{k}\right) \equiv \sum_{j} \pi^{j}\left(z\left(\alpha_{k}\right), \alpha_{k}\right) u^{\prime}\left(c\left(\alpha_{k}, w_{j}\right)\right)-\psi \sigma\left(z\left(\alpha_{k}\right), \alpha_{k}\right) \Delta u^{\prime}\left(c\left(\alpha_{k}\right)\right)
$$

and

$H\left(\alpha_{k}\right) \equiv f\left(\alpha_{k}\right) \sum_{k^{\prime}} \chi\left(\alpha_{k}, \alpha_{k^{\prime}}\right)-\sum_{k^{\prime}} f\left(\alpha_{k^{\prime}}\right) \chi\left(\alpha_{k^{\prime}}, \alpha_{k}\right) \frac{\left\{\pi_{z}^{H}\left(z\left(\alpha_{k}\right), \alpha_{k^{\prime}}\right)-\psi \sigma_{z}\left(z\left(\alpha_{k}\right), \alpha_{k^{\prime}}\right)\right\}}{\left\{\pi_{z}^{H}\left(z\left(\alpha_{k}\right), \alpha_{k}\right)-\psi \sigma_{z}\left(z\left(\alpha_{k}\right), \alpha_{k}\right)\right\}}$.

The wedge $S^{\prime}\left(\alpha_{k}\right)$ is hence influenced by a number of factors. First, the difference between the social and private value of resources to type $\alpha_{k}$ is measured by the ratio $\lambda / \kappa\left(\alpha_{k}\right)$. As noted above, in Scenario 1, $\lambda$ is equal to the harmonic mean marginal utility of consumption for each ability type. The private value, $\kappa\left(\alpha_{k}\right)$, equals the arithmetic mean when the agent is not disappointment averse and exceeds the arithmetic mean when $\psi>0$. Hence, in Scenario 1, every ability type values resources carried forward into adulthood more than the social planner does, $\lambda<\kappa\left(\alpha_{k}\right)$. The logic is clear: the social planner would allocate additional consumption generate equal utility increases at each wage realization in order to maintain wage reporting incentives. Savings, in contrast,

\footnotetext{
${ }^{20}$ The proof, which uses the first order conditions (A10) - (A13), is standard and hence omitted.
} 
increase consumption by equal amounts at each wage realization and thus reduce the utility gap. With unobservable ability (Scenario 2) higher ability types will be tempted to mimic lower types, leading to the possibility of $\lambda / \kappa\left(\alpha_{k}\right)$ exceeding unity for the higher types.

Second, consider the term $H\left(\alpha_{k}\right)$ (which is non-zero only in the case of unobservable ability). This term effectively measures whether type $\alpha_{k}$ is more tempted to mimic others than others are tempted to mimic type $\alpha_{k}$. A higher value of $H\left(\alpha_{k}\right)$ increases $S^{\prime}\left(\alpha_{k}\right)$ ceteris paribus. Hence, since we expect higher ability types to be tempted to mimic lower ability types, this will lead to relatively more encouragement of education for high ability types.

Third, $S^{\prime}\left(\alpha_{k}\right)$ depends on the relative rates of return on education and savings. The higher is $\rho\left(\alpha_{k}\right) / r$, the more investments in education should be encouraged. The final factor in $S^{\prime}\left(\alpha_{k}\right)$ is the effective marginal tax rate, $T_{\Delta}^{\prime}\left(\alpha_{k}\right)$. Its presence in the expression for the optimal education policy is reminiscent of Bovenberg and Jacobs (2005), who show that education is optimally encouraged so as to counteract the disincentives for human capital investments generated by the optimal earnings tax.

\subsection{Numerical Example}

Although the terms in (18) can be given interpretations, they do not provide a clear intuition for the distinction between risk- and disappointment aversion and by the potential non-observability of ability. In order to provide further insight, we therefore carry the numerical example forward. Three key intuitions are brought out by the simple example.

First, disappointment aversion is an ex ante risk concept: once the risk has been resolved, it no longer influences the individuals' behaviour. To see this, consider the wage reporting constraints (12). These constraints - which represent the constraints put on the optimal tax system by ex post labour supply incentives - are structurally unaffected by the presence of disappointment aversion. This means that, when contrasting the disappointment aversion case $(\psi>0, \gamma=1)$ to the baseline case $(\psi=0, \gamma=1)$, although the individuals do have stronger demand for earnings insurance, the provision 
of such insurance is still constrained by the same ex post labour supply incentives. This is in sharp contrast to the case of high risk aversion, $(\psi=0, \gamma>1)$ as risk aversion is encoded in the curvature of the individuals' preferences, which continue to guide their labour supply behaviour once the risk has been resolved. In particular, a high degree of relative risk aversion implies a low elasticity of substitution between consumption and leisure 21 This in turn relaxes the labour supply incentive constraints captured by (12). Hence, while both disappointment- and higher risk-aversion imply ex ante demand for earnings insurance, more generous insurance can be provided in the latter case. In the example below, this will be reflected in higher effective marginal tax rates under high risk aversion than under disappointment aversion.

Second, the lower optimal level of earnings insurance under disappointment aversion in turn discourages (encourages) investments in education by low (high) ability individuals in much the same way as in laissez-faire. In order to bring the individual's investments closer to the socially efficient levels, the optimal policy therefore, in net terms, encourages investments by low ability individuals and discourages it for high ability individuals. In contrast, under standard expected utility with high risk aversion, the main role of the optimal education policy is to compensate for the disincentives generated by the earnings tax as in Bovenberg and Jacobs (2005).

Third, under unobservable ability, higher ability individuals are tempted to mimick lower ability peers. A typical feature of constrained optimal allocations is that, in order to relax the binding self-selection constraints, they distort the behaviour of types who are being mimicked in directions which hurt the mimicker more than the true type 22 Here, high ability agents have, due to the complementarity between education and ability, a stronger marginal benefit from education than do low ability agents. In order to relax the ex ante incentive constraints, the optimal allocation thus net discourages educational

\footnotetext{
${ }^{21}$ The inverse relationship between relative risk aversion and the elasticity of substitution under additive preferences is well known not least from the standard inter-temporal model. In that context, is has previously been noted that non-expected utility will relax that relationship. See e.g. Weil (1990).

${ }^{22}$ This intuition underlies the positive marginal tax rate on earnings for low ability types in Proposition 3 (Stiglitz, 1982).
} 
investments by low ability individuals. In the example provided, this effect dominates in the case of high risk aversion, but fails to overturn the optimality of net education subsidies for low ability individuals in the case of disappointment aversion.

We will illustrate these effects by showing, in turn, the marginal effective tax rates, the rates of return to education, and the net education subsidies for each ability type under each preference and information scenario.

4.3.1. Tax Pressure Figure 4 shows the effective marginal tax rate $T_{\Delta}^{\prime}\left(\alpha_{k}\right)$ defined in (16) at the social optimum for each ability type. The left panel shows the case of observable ability ("Scenario 1") while the right panel shows the case of unobservable ability ("Scenario 2"). Within each panel, the line with starred markers shows the baseline case $(\psi=0, \gamma=1)$, the circle markers shows the case with disappointment aversion $(\psi=0.65, \gamma=1)$, and the line with square markers shows the case of "high" risk aversion $(\psi=0, \gamma=3.5)$.

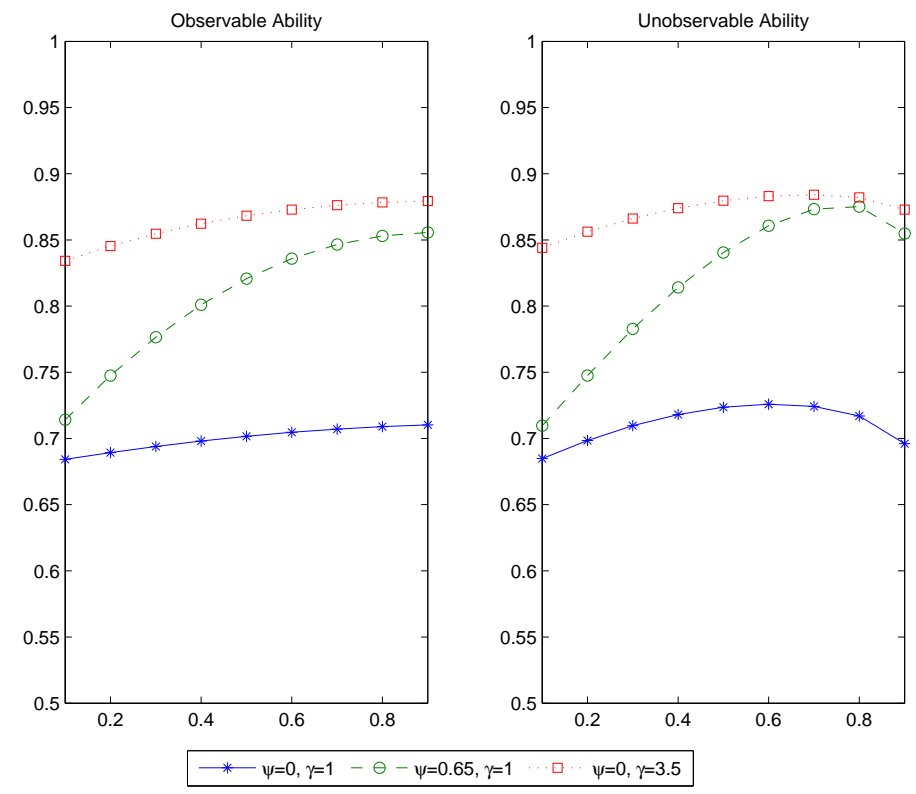

Figure 4: The optimal effective marginal tax rate on earnings in the baseline case $(\psi=$ $0, \gamma=1)$, with disappointment aversion $(\psi=0.65, \gamma=1)$, and with larger risk aversion $(\psi=0, \gamma=3.5)$ with observable- and unobservable ability respectively. 
In the baseline case $T_{\Delta}^{\prime}\left(\alpha_{k}\right)$ is fairly constant across ability types, a feature that holds in either information scenario. Introducing stronger preference against risk, and hence demand for earnings insurance, either in the form of larger risk aversion or in the form of disappointment aversion leads, as intuition would suggest, to more redistribution between the wage states as indicated by a higher effective marginal tax rate. However, as noted above, this effect is more pronounced under high risk aversion (and thus lower elasticity of substitution) than under disappointment aversion which does not alter the ex post preferences over consumption and leisure.

4.3.2. Rates of Return to Education Figure 5 shows the rate of return to education for each ability at the social optimum.

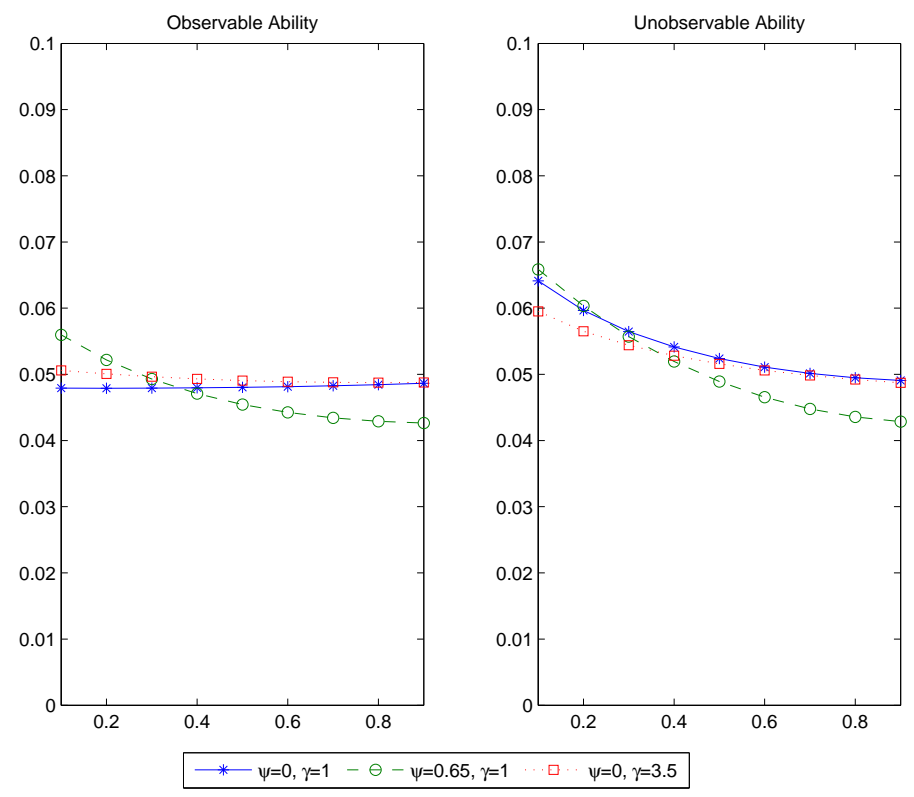

Figure 5: Rate of return to education in baseline case $(\psi=0, \gamma=1)$, with disappointment aversion $(\psi=0.65, \gamma=1)$, and with larger risk aversion $(\psi=0, \gamma=3.5)$ at the optimal allocation with observable- and unobservable ability respectively.

Under observable ability and without disappointment aversion, the return to education is effectively equalized to the return on savings for every ability type, even with higher risk aversion. In contrast, under disappointment aversion, a negative ability gradient remains 
although it is much reduced relative to the laissez-faire equilibrium. With unobservable ability a negative ability gradient occurs for all preference settings as the investment in education for lower ability types is marginally discouraged in order to encourage selfselection by higher ability types.

4.3.3. Optimal Investment Wedge Figure 6 shows the "net" education subsidy rate, defined as $\left[S^{\prime}\left(\alpha_{k}\right)-T_{\Delta}^{\prime}\left(\alpha_{k}\right)\right] / T_{\Delta}^{\prime}\left(\alpha_{k}\right)$.

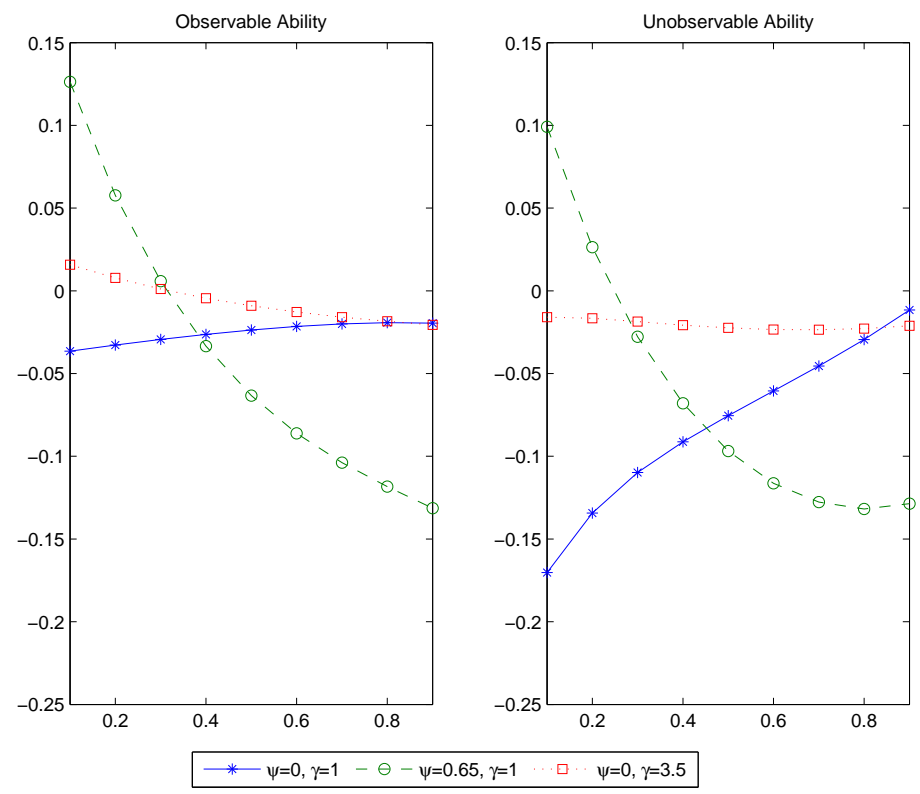

Figure 6: The optimal net encouragement of education in the baseline case $(\psi=0, \gamma=1)$, with disappointment aversion $(\psi=0.65, \gamma=1)$, and with larger risk aversion $(\psi=0, \gamma=$ 3.5), with observable- and unobservable ability respectively.

Under observable ability, the net education subsidy rate is close to zero both in the baseline case and under high risk aversion. Hence in the absence of disappointment aversion, the role of the education subsidy is thus mainly to counteract the disincentives for education generated by the earnings tax. In contrast, under disappointment aversion the optimal policy quite strongly net encourages (discourages) investments in education by low (high) ability types.

Under unobservable abilities, the associated optimal downward distortion of the ed- 
ucational investments for low ability individuals implies that the net education subsidy rates for low ability individuals is lower than under observable ability in all preference settings. As a result, in the baseline case, the educational investments by low ability individuals are markedly net discouraged. The same effect also slightly reduces the net educational subsidies for low ability individuals under high risk aversion and under disappointment aversion, but in the latter case in particular, it does not overturn the optimality of substantial positive net subsidies.

\section{Conclusions}

To date, surprisingly little work has been done to explore the potential role of behavioural economics for individuals' choices with respect to education and for education policy. This is somewhat surprising given the heavy focus in behavioural economics on risk and time preferences. Casual inspection suggests that time inconsistent behaviour and/or deviations from expected utility may well provide strong justifications for policies to encourage individuals to stay in school longer. However, the simple models need to be floated into more complete environments before they can be taken as guide to policy.

In this paper we have taken steps in this direction. In particular, we have taken a basic model of loss aversion and considered the roles played by endogenous reference points (disappointment aversion), basic risk aversion and its relationship to labour supply behaviour, and potential non-observability of ability.

This has provided several insights into how the exact nature of individuals' risk preferences, the risk properties of education, and the information structure critically shape optimal policy. Thus the paper contributes to a growing literature that explores normative public policy under non-standard preferences. However, it also exposes a lack of empirical evidence. This was illustrated in the paper by showing that the observed educational choices in a well-known data set - the NCDS - are equally well rationalized by disappointment aversion as by "high" risk aversion. This suggests that observational data alone is unlikely to identify the nature of individuals' risk preferences. Similarly, the empirical evidence on the risk properties of education is still limited, not to mention 
evidence on what determines individuals' aspirations. Research combining behavioural economics and education in particular is still in its infancy, and hopefully analysis such as that presented here can provide impetus for further empirical and theoretical work.

\section{REFERENCES}

Akerlof, G. (1978), "The economics of "tagging" as applied to the optimal income tax, welfare programs, and manpower planning', American Economic Review 68, 8-19.

Anderberg, D. (2009), 'Optimal policy and the risk properties of human capital reconsidered', Journal of Public Economics 93, 1017-1026.

Bell, D. E. (1985), 'Disappointment in decision making under uncertainty', Operations Research 33, 1-27.

Bernheim, B. D. \& Rangel, A. (2005), 'Behavioral public economics: Welfare and policy analysis with non-standard decision-makers', NBER Working Papers 11518, National Bureau of Economic Research.

Blundell, R., Dearden, L. \& Sianesi, B. (2004), 'Evaluating the impact of education on earnings in the uk: models, methods and results from the NCDS', The Institute for Fiscal Studies WP03/20.

Bovenberg, A. \& Jacobs, B. (2005), 'Redistribution and education subsidies are siamese twins', Journal of Public Economics 87, 1521-1537.

Brewer, M., Saez, E. \& Shephard, A. (2010), Means-testing and tax rates on earnings: a contribution to the Mirrlees review, in 'Dimensions of Tax Design', Oxford University Press.

Card, D. (2001), 'Estimating the returns to schooling: progress on some persistent econometric problems', Econometrica 69, 1127-1170.

Carneiro, P. \& Heckman, J. (2002), 'The evidence on credit constraints in post-secondary schooling', Economic Journal 112, 705-773. 
Chetty, R. (2006), 'A new method of estimating risk aversion', American Economic Review 96, 1821-1834.

da Costa, C. E. \& Maestri, L. J. (2007), 'The risk properties of human capital and the design of government policies', European Economic Review 51, 695-713.

Dearden, L., McGranahan, L. \& Sianesi, B. (2004), 'The role of credit constraints in educational choices: evidence from NCDS and BCS70', Centre for the Economics of Education DP 48.

Delquie, P. \& Cillo, A. (2006), 'Expectations, disappointment and rank-depended probability weighting', Theory and Decision 60, 193-206.

Findeisen, S. \& Sachs, D. (2013), 'Education and optimal dynamic taxation: The role of income-contingent student loans', University of Mannheim, Mimeo.

Gill, D. \& Prowse, V. (2012), 'A structural analysis of disappointment aversion in a real effort competition', American Economic Review 102, 469-503.

Jacobs, B. \& Bovenberg, L. (2011), 'Optimal taxation of human capital and the earnings function', Journal of Public Economic Theory 13, 957-971.

Jacobs, B., Shindler, D. \& Yang, H. (2012), 'Optimal taxation of risky human capital', Scandinavian Journal of Economics 114, 908-931.

Kahneman, D., Knetsch, J. L. \& Thaler, R. (1991), 'The endowment effect, loss aversion and status quo bias', The Journal of Economic Prospectives 5(1), 193-206.

Kahneman, D. \& Tversky, A. (1979), 'Prospect theory: an analysis of decision under risk', Econometrica 47(2), 263-291.

Kane, T. (2001), 'College-going and inequality: a literature review', Working paper, Russell Sage Foundation.

Kocherlakota, N. (2006), Advances in dynamic optimal tax, in 'Advances in Economics and Econometrics Theory and Applications, Ninth World Congress Volume 1'. 
Kocherlakota, N. R. (2010), The New Dynamic Public Finance, Princeton University Press.

Koszegi, B. \& Rabin, M. (2006), 'A model of reference-dependent preferences', Quarterly Journal of Economics 121, 1133-1165.

Koszegi, B. \& Rabin, M. (2007), 'Reference-dependent risk attitudes', American Economic Review 97, 1047-1073.

Laibson, D. (1997), 'Golden eggs and hyperbolic discounting', Quarterly Journal of Economics 112, 443-477.

Lavecchia, A. M., Liu, H. \& Oreopoulos, P. (2014), 'Behavioral economics of education: Progress and possibilities', NBER Working Paper No. 20609.

Lecouteux, G. \& Moulin, L. (2014), 'To gain or not to lose? Tuition fees for loss averse students', Mimeo, Universit Paris 7 Diderot.

Levhari, D. \& Weiss, Y. (1974), 'The effect of risk on the investment in human capital', American Economic Review 64, 950-963.

Loomes, G. \& Sugden, R. (1986), 'Disappointment and dynamic consistency in choice under uncertainty', Review of Economic Studies 53, 271-282.

Mirrlees, J. A. (1971), 'An exploration in the theory of optimum income taxation', Review of Economic Studies 38, 175-208.

O’Donoghue, T. \& Rabin, M. (2001), Risky behavior among youths: Some issues from behavioral economics, in J. Gruber, ed., 'Risky Behavior among Youths: An Economic Analysis', University of Chicago Press.

Oreopoulos, P. \& Salvanes, K. (2011), 'Priceless: The nonpecuniary benefits of schooling', Journal of Economic Perspectives 25, 159-184. 
Skyt-Nielsen, H. \& Vissing-Jorgensen, A. (2010), 'The impact of labor income risk on educational choices: Estimates and implied risk aversion'. Mimeo, University of Aarhus.

Stiglitz, J. (1982), 'Self-selection and Pareto efficient taxation', Journal of Public Economics 17, 213-240.

Taylor, M. \& Rampino, T. (2014), 'Educational aspirations and attitudes over the business cycle', Economica 81(324), 649-673.

Weil, P. (1990), 'Nonexpected utility in macroeconomics', Quarterly Journal of Economics 105, 29-42. 


\section{Appendix A: Further Details of the Empirical Illustration}

Sample Selection: Our sample includes all male NCDS cohort members who (i) reported to have left full time education between the ages of 16 and 24, (ii) for whom we observe an hourly gross wage at age 33, and (iii) for whom there is an available score on each of three tests taken at age 11: a general ability test, a math test and a reading test. This leaves us with a sample of 2,632 males.

Ability Measure: Each of the three ability test scores is first normalized. The normalized scores are then added together. Finally, the sample is split into quartiles, $\alpha \in A=$ $\left\{\alpha_{1}, \alpha_{2}, \alpha_{3}, \alpha_{4}\right\}$, based on the summed score.

Measure of Educational Investment: We use the age at which the respondent left full time education as a measure of educational investment. This is justified on the grounds that the main cost of education to the individual is forgone earnings. We discretize this variable, denoted $z \in Z$, into three groups: $z_{0}$ is defined as leaving school at the minimum school-leaving age of $16, z_{1}$ is defined as leaving school at 17 or 18 , and $z_{2}$ is defined as leaving school at the age of 19 or later. This discretization mirrors the UK academic degree structure. An individual leaving at the age of 16 would have typically left with a basic secondary school degree - an O-level degree or a Certificate of Secondary Education - or no academic qualification at all. An individual leaving at the age of 17 or 18 would typically leave with an A-level degree. Students staying on past the age of 18 would generally be enrolled in some form of tertiary (or "higher") education leading to a degree. We associate $z_{0}, z_{1}$ and $z_{2}$ with 0,2 and 5 years of post-compulsory schooling respectively, the mode number of years in the data in each group.

Further Demographic Controls: In order to explore the robustness with respect to including controls for demographic characteristics, we further use information on the school leaving age of the respondent's father and mother (for simplicity discretized into the same categories) and on the respondent's number of siblings (at age 7). Among the respondents' fathers, 78 percent left school at 16, 14 percent between 17-18, and 8 percent stayed on until age 19 or above. Among the respondents' mothers, the corresponding 
fractions were 78,17 , and 5 percent respectively. The average number of siblings was 2.94. When using these demographic controls, our sample size reduces to 1,807 .

Conceptual Framework: Each individual $i$ chooses an education level from the set $Z$ knowing her ability $\alpha_{i}$. In doing so, she expects that choosing $z_{j}$ will lead her to obtain a wage drawn from a distribution $w_{i j} \sim F\left(w \mid \alpha_{i}, z_{j}\right)$. It is assumed that the individual has no information about her potential earnings beyond knowing $\alpha_{i}$, and that she, in addition to earnings expectations, bases her choice on idiosyncratic non-pecuniary utility factors which are, conditional on ability, uncorrelated with potential wages. Consistent with this assumption we use the empirical distributions of wages to characterize $F(w \mid \alpha, z)$ for each $(\alpha, z)$-cell.

For simplicity we ignore wage growth and assume that the individuals (i) discount future income at rate $r$, and (ii) can sustain a stable level of consumption which is proportional to the net present value of earnings, $c_{i j} \propto w_{i j}(1+r)^{-z_{j}}$, as measured from the compulsory school leaving age.

Disappointment Aversion: Here we impose log utility (unit relative risk aversion) $u\left(c_{i j}\right)=\ln \left(c_{i j}\right)$. Disappointment aversion is modelled as loss aversion around the agent's expected outcome as specified in (11). Consider then taking the expected value of $U$ conditional on $\alpha_{i}$ and $z_{j}$ (which we thus suppress in the notation below). Note that, from (1), $U$ can be written as

$$
U=u+\psi^{L}\{u-E[u]\} I_{\{u<E[u]\}}+\psi^{H}\{u-E[u]\} I_{\{u \geq E[u]\}},
$$

where $I\{\cdot\}$ is the indicator function. Taking the expected value of $U$ requires us to take expectations of the last two terms in (A1). To this end we note that

$$
E\left[\{u-E[u]\} I_{\{u<E[u]\}}\right]=\operatorname{Pr}\{u<E[u]\}\{E[u \mid u<E[u]]-E[u]\}
$$

Substituting for $E[u]=\operatorname{Pr}\{u<E[u]\} E[u \mid u<E[u]]+\operatorname{Pr}\{u \geq E[u]\} E[u \mid u \geq E[u]]$ and collecting terms then yields that

$E\left[\{u-E[u]\} I_{\{u<E[u]\}}\right]=-\operatorname{Pr}\{u<E[u]\} \operatorname{Pr}\{u \geq E[u]\}\{E[u \mid u \geq E[u]]-E[u \mid u<E[u]]\}$ 
By a similar logic

$E\left[\{u-E[u]\} I_{\{u \geq E[u]\}}\right]=\operatorname{Pr}\{u \geq E[u]\} \operatorname{Pr}\{u<E[u]\}\{E[u \mid u \geq E[u]]-E[u \mid u<E[u]]\}$

Using (A3) and (A4) then yields that

$$
E[U]=E[u]-\psi \operatorname{Pr}\{u<E[u]\} \operatorname{Pr}\{u \geq E[u]\}\{E[u \mid u \geq E[u]]-E[u \mid u<E[u]]\}
$$

where we used that $\psi=\psi^{L}-\psi^{H}$. Next we use that $c \propto w(1+r)^{-z}$ whereby $u(c)=$ $\ln c=\ln w-z \ln (1+r)$ plus some constant. Under the assumption that $\ln w$ (conditional on $\alpha$ and $z$ ) is normally distributed, so is $u(c)$ and with the same variance. From the properties of the normal distribution it follows that $\operatorname{Pr}\{u<E[u]\}=\operatorname{Pr}\{u \geq E[u]\}=1 / 2$ and $E[u \mid u \geq E[u]]-E[u \mid u<E[u]]=4 * \operatorname{StDev}\left[\ln w \mid \alpha_{i}, z_{j}\right] / \sqrt{2 \pi}$. Substituting into the expression for $E[U]$ yields (2) .

Individual $i$ also has idiosyncratic non-pecuniary utility from each possible education choice which we assume takes the form $\zeta_{j} x_{i}+\varepsilon_{i j}$, where $x_{i}$ is the vector of observable demographic characteristics and $\varepsilon_{i j}$ is unobservable (to the researcher, but known to the individual). Hence we model the expected utility to individual $i$ from choosing option $z_{j}$ as

$$
V_{i j}+\varepsilon_{i j}=\kappa E\left[U\left(w_{i j}\right) \mid z_{j}, \alpha_{i}\right]+\zeta_{j} x_{i}+\varepsilon_{i j}
$$

or, substituting,

$$
V_{i j}+\varepsilon_{i j}=\kappa E\left[\ln \left(w_{i j}\right)-z_{j} \ln (1+r) \mid \alpha_{i}, z_{j}\right]-\kappa \psi \frac{S t D e v\left[\ln \left(w_{i j}\right) \mid \alpha_{i}, z_{j}\right]}{\sqrt{2 \pi}}+\zeta_{j} x_{i}+\varepsilon_{i j} .
$$

Under the assumption that $\varepsilon_{i j}$ follows a type I extreme value distribution our model is a version of a conditional logit where the estimate of $\psi$ is given by the ratio between the coefficient on the (scaled) standard deviation and the (discounted) expected log wage.

Risk Aversion: When modelling arbitrary relative risk aversion the log utility is replaced by $u\left(c_{i j}\right)=c_{i j}^{1-\gamma} /(1-\gamma)$ and $\psi$ is set to zero. In line with the previous case we assume that the ex ante utility of individual $i$ from choosing $z_{j}$ can be written as

$$
V_{i j}+\varepsilon_{i j}=\kappa E\left[u\left(c_{i j}\right) \mid z_{j}, \alpha_{i}\right]+\zeta_{j} x_{i}+\varepsilon_{i j}
$$


This is again a version of a conditional logit model, but one where the relative risk aversion parameter enters non-linearly.

Estimates: Both models are estimated using maximum likelihood. Since the estimation makes use of moments estimated from the data, we present bootstrapped standard errors. All models are estimated on the sample for which demographic information is available. The estimates are provided in Table 1 .

Model Fit: Table 2 shows the actual choice frequencies by ability group in the NCDS data, along with the simulated choice frequencies from the two alternative empirical models: the model with disappointment aversion (and unit relative risk aversion) and the model with constant relative risk aversion preferences (but not disappointment aversion), in each case the specification without demographic controls and common preferences across ability groups.

\section{Appendix B: Proofs}

Proof of Proposition 1. With $\psi=0$, the first order condition for the individual's choice of $z$ in laissez-faire can be written as $\pi_{z}^{H} \Delta v=r w_{0} E\left[u^{\prime}(c)\right]$, where $\Delta v \equiv\left(v_{H}-v_{L}\right)$. Combining it with (6) yields

$$
\frac{\rho(a)}{r} \equiv \frac{\Delta w E[l] E\left[u^{\prime}(c)\right]}{\Delta v}
$$

For type $\alpha_{1}$, by Assumption 2, $E[l] E\left[u^{\prime}(c)\right] \simeq l_{L} u^{\prime}\left(c_{L}\right)$ whereby $\rho\left(a_{1}\right)>r$ if and only if $\Delta v<\Delta w l_{L} u^{\prime}\left(c_{L}\right)$. To see that this is true note that $\Delta v<\Delta w v_{w}\left(w_{L}, r s\right) \simeq \Delta w u^{\prime}\left(c_{L}\right) l_{L}$ where the inequality follows from the fact that $v(\cdot, \cdot)$ is concave in $w$. A parallel argument applies for type $\alpha_{N}$. \#

Proof of Proposition 2, By standard comparative statics argument, $\partial z^{*}(\alpha) / \partial \psi$ has the same sign as the cross-partial derivative of the individual's objective function. Taking this cross-partial yields $-\sigma_{z}(z, \alpha) \Delta v+r w_{0} \sigma(z, \alpha) \Delta v_{z}$. However, by Assumption 2, $\sigma\left(z^{*}\left(a_{j}\right), a_{j}\right)$ is negligible for both the lowest and the highest type. The result then follows from the fact that $\sigma_{z}(z, \alpha)=\pi_{z}^{H}(z, \alpha)\left[1-2 \pi^{H}(z, \alpha)\right]$ and Assumptions 1 and 2 , \# 
First Order Conditions for the Constrained Optimal Allocation. We let $\lambda$ denote the multiplier on the aggregate resource constraint, $\mu\left(\alpha_{k}\right)$ the multiplier on the wagereporting constraint for type $\alpha_{k}$, and $\chi\left(\alpha_{k}, \alpha_{k^{\prime}}\right)$ the multiplier on the constraint that type $\alpha_{k}$ should not prefer to mimic type $\alpha_{k^{\prime}}$. In scenario 1 ("observable ability"), $\chi\left(\alpha_{k}, \alpha_{k^{\prime}}\right)=0$ for all ability types.

For consumption we obtain

$$
\begin{aligned}
\frac{\lambda}{u^{\prime}\left(c\left(\alpha_{k}, w_{H}\right)\right)}= & {\left[1-\psi \pi^{L}\left(z\left(\alpha_{k}\right), \alpha_{k}\right)\right]\left(1+\sum_{k^{\prime}} \chi\left(\alpha_{k}, \alpha_{k^{\prime}}\right)\right)+\mu\left(\alpha_{k}\right) } \\
& -\sum_{k^{\prime}} \frac{f\left(\alpha_{k^{\prime}}\right)}{f\left(\alpha_{k}\right)} \chi\left(\alpha_{k^{\prime}}, \alpha_{k}\right) \frac{\pi^{H}\left(z\left(\alpha_{k}\right), \alpha_{k^{\prime}}\right)}{\pi^{H}\left(z\left(\alpha_{k}\right), \alpha_{k}\right)}\left[1-\psi \pi^{L}\left(z\left(\alpha_{k}\right), \alpha_{k^{\prime}}\right)\right],
\end{aligned}
$$

and

$$
\begin{aligned}
\frac{\lambda}{u^{\prime}\left(c\left(\alpha_{k}, w_{L}\right)\right)}= & {\left[1+\psi \pi^{H}\left(z\left(\alpha_{k}\right), \alpha_{k}\right)\right]\left(1+\sum_{k^{\prime}} \chi\left(\alpha_{k}, \alpha_{k^{\prime}}\right)\right)-\frac{\pi^{H}\left(z\left(\alpha_{k}\right), \alpha_{k}\right)}{\pi^{L}\left(z\left(\alpha_{k}\right), \alpha_{k}\right)} \mu\left(\alpha_{k}\right) } \\
& -\sum_{k^{\prime}} \frac{f\left(\alpha_{k^{\prime}}\right)}{f\left(\alpha_{k}\right)} \chi\left(\alpha_{k^{\prime}}, \alpha_{k}\right) \frac{\pi^{L}\left(z\left(\alpha_{k}\right), \alpha_{k^{\prime}}\right)}{\pi^{L}\left(z\left(\alpha_{k}\right), \alpha_{k}\right)}\left[1+\psi \pi^{H}\left(z\left(\alpha_{k}\right), \alpha_{k^{\prime}}\right)\right] . \quad \text { (A11) }
\end{aligned}
$$

For earnings we obtain

$$
\begin{array}{r}
\frac{\lambda}{\nu^{\prime}\left(1-\frac{y\left(\alpha_{k}, w_{H}\right)}{w_{H}}\right) \frac{1}{w_{H}}}=\left[1-\psi \pi^{L}\left(z\left(\alpha_{k}\right), \alpha_{k}\right)\right]\left(1+\sum_{k^{\prime}} \chi\left(\alpha_{k}, \alpha_{k^{\prime}}\right)\right)+\mu\left(\alpha_{k}\right) \\
-\sum_{k^{\prime}} \frac{f\left(\alpha_{k^{\prime}}\right)}{f\left(\alpha_{k}\right)} \chi\left(\alpha_{k^{\prime}}, \alpha_{k}\right) \frac{\pi^{H}\left(z\left(\alpha_{k}\right), \alpha_{k^{\prime}}\right)}{\pi^{H}\left(z\left(\alpha_{k}\right), \alpha_{k}\right)}\left[1-\psi \pi^{L}\left(z\left(\alpha_{k}\right), \alpha_{k^{\prime}}\right)\right],
\end{array}
$$

and

$$
\begin{aligned}
& \frac{\lambda}{\nu^{\prime}\left(1-\frac{y\left(\alpha_{k}, w_{L}\right)}{w_{L}}\right) \frac{1}{w_{L}}}=\left[1+\psi \pi^{H}\left(z\left(\alpha_{k}\right), \alpha_{k}\right)\right]\left(1+\sum_{k^{\prime}} \chi\left(\alpha_{k}, \alpha_{k^{\prime}}\right)\right) \\
&-\mu\left(\alpha_{k}\right) \frac{\pi^{H}\left(z\left(\alpha_{k}\right), \alpha_{k}\right)}{\pi^{L}\left(z\left(\alpha_{k}\right), \alpha_{k}\right)} \frac{\nu^{\prime}\left(1-\frac{y\left(\alpha_{k}, w_{L}\right)}{w_{H}}\right) \frac{1}{w_{H}}}{\nu^{\prime}\left(1-\frac{y\left(\alpha_{k}, w_{L}\right)}{w_{L}}\right) \frac{1}{w_{L}}} \\
&-\sum_{k^{\prime}} \frac{f\left(\alpha_{k^{\prime}}\right)}{f\left(\alpha_{k}\right)} \chi\left(\alpha_{k^{\prime}}, \alpha_{k}\right) \frac{\pi^{L}\left(z\left(\alpha_{k}\right), \alpha_{k^{\prime}}\right)}{\pi^{L}\left(z\left(\alpha_{k}\right), \alpha_{k}\right)}\left[1+\psi \pi^{H}\left(z\left(\alpha_{k}\right), \alpha_{k^{\prime}}\right)\right] .
\end{aligned}
$$


For the investment level $z\left(a_{k}\right)$ we have

$$
\begin{aligned}
& \lambda \frac{r w_{0}-\pi_{z}^{H}\left(z\left(\alpha_{k}\right), \alpha_{k}\right)\left[\Delta y\left(\alpha_{k}\right)-\Delta c\left(\alpha_{k}\right)\right]}{\Delta v\left(\alpha_{k}\right)} \\
&=\left[\pi_{z}^{H}\left(z\left(\alpha_{k}\right), \alpha_{k}\right)-\psi \sigma_{z}\left(z\left(\alpha_{k}\right), \alpha_{k}\right)\right]\left(1+\sum_{k^{\prime}} \chi\left(\alpha_{k}, \alpha_{k^{\prime}}\right)\right) \\
& \quad-\sum_{k^{\prime}} \frac{f\left(\alpha_{k^{\prime}}\right)}{f\left(\alpha_{k}\right)} \chi\left(\alpha_{k^{\prime}}, \alpha_{k}\right)\left[\pi_{z}^{H}\left(z\left(\alpha_{k}\right), \alpha_{k^{\prime}}\right)-\psi \sigma_{z}\left(z\left(\alpha_{k}\right), \alpha_{k^{\prime}}\right)\right] .
\end{aligned}
$$

\#

\section{Proof of Proposition 4}

Rewrite (A14) as

$$
\begin{aligned}
& {\left[\pi_{z}^{H}\left(z\left(\alpha_{k}\right), \alpha_{k}\right)-\psi \sigma_{z}\left(z\left(\alpha_{k}\right), \alpha_{k}\right)\right] \Delta} \\
& \quad=\frac{\lambda}{\left\{1+H\left(\alpha_{k}\right) / f\left(\alpha_{k}\right)\right\}}\left\{r w_{0}-\pi_{z}^{H}\left(z\left(\alpha_{k}\right), \alpha_{k}\right)\left[\Delta y\left(\alpha_{k}\right)-\Delta c\left(\alpha_{k}\right)\right]\right\}
\end{aligned}
$$

with $H\left(\alpha_{k}\right)$ defined as in (20). Next substitute into the definition (15) to obtain

$$
S^{\prime}\left(\alpha_{k}\right)=1-\frac{\lambda}{\left\{1+H\left(\alpha_{k}\right) / f\left(\alpha_{k}\right)\right\}} \frac{1}{r} \frac{\left\{r w_{0}-\pi_{z}^{H}\left(z\left(\alpha_{k}\right), \alpha_{k}\right)\left[\Delta y\left(\alpha_{k}\right)-\Delta c\left(\alpha_{k}\right)\right]\right\}}{w_{0} \kappa\left(\alpha_{k}\right)}
$$

where $\kappa\left(\alpha_{k}\right)$ is defined as in (19). Finally, using that $\Delta T\left(\alpha_{k}\right) \equiv \Delta y\left(\alpha_{k}\right)-\Delta c\left(\alpha_{k}\right)$, rearranging and extending yields that

$$
\begin{aligned}
& S^{\prime}\left(\alpha_{k}\right) \equiv 1- \\
& \frac{\lambda}{\kappa\left(\alpha_{k}\right)} \frac{1}{\left\{1+H\left(\alpha_{k}\right) / f\left(\alpha_{k}\right)\right\}}\left[1-\frac{1}{r} \frac{\pi_{z}^{H}\left(z\left(\alpha_{k}\right), \alpha_{k}\right) \Delta w E\left[l\left(\alpha_{k}\right)\right]}{w_{0}} \frac{\Delta T\left(\alpha_{k}\right)}{\Delta w E\left[l\left(\alpha_{k}\right)\right]}\right] .
\end{aligned}
$$

The result then follows from the definitions (6) and (16). \# 
Table 1: Estimates of Risk Aversion and Disappointment Aversion

\begin{tabular}{lccccc}
\hline \hline \multirow{2}{*}{ Specification } & \multicolumn{2}{c}{ Relative Risk Aversion } & & \multicolumn{2}{c}{ Disappointment Aversion } \\
Common Preferences & 3.89 & 3.54 & 0.62 & 0.54 \\
& $(0.07)$ & $(0.11)$ & $(0.04)$ & $(0.13)$ \\
\hline Ability type $\alpha_{1}$ & 3.65 & 3.72 & 0.59 & 0.50 \\
& $(0.11)$ & $(0.18)$ & $(0.04)$ & $(0.15)$ \\
Ability type $\alpha_{2}$ & 3.69 & 3.75 & 0.58 & 0.51 \\
& $(0.10)$ & $(0.17)$ & $(0.04)$ & $(0.15)$ \\
Ability type $\alpha_{3}$ & 3.84 & 3.88 & 0.62 & 0.55 \\
& $(0.12)$ & $(0.15)$ & $(0.04)$ & $(0.15)$ \\
Ability type $\alpha_{4}$ & 3.93 & 3.95 & 0.62 & 0.56 \\
& $(0.33)$ & $(0.13)$ & $(0.04)$ & $(0.15)$ \\
\hline Family controls & No & Yes & No & Yes \\
\hline Nr Obs & & & 1,807 & \\
\hline \hline
\end{tabular}

Notes. - Family controls include number of siblings and four dummy variables for parents' education (father leaving FTE aged 17-18, father leaving FTE aged 19+, mother leaving FTE aged 17-18, mother leaving FTE aged 19+). All estimates are by maximum likelihood. Bootstrapped standard errors in parenthesis.

Table 2: Observed and Simulated Education Choices

\begin{tabular}{|c|c|c|c|c|c|c|c|c|c|}
\hline & \multirow{2}{*}{\multicolumn{3}{|c|}{$\frac{\text { NCDS Actual }}{\underline{\text { Data }}}$}} & \multirow{2}{*}{\multicolumn{3}{|c|}{$\frac{\text { "Disappointment }}{\text { Model" }}$}} & \multirow{2}{*}{\multicolumn{3}{|c|}{$\frac{\text { "Risk Aversion }}{\text { Model" }}$}} \\
\hline & & & & & & & & & \\
\hline & $z_{0}$ & $z_{1}$ & $z_{2}$ & $z_{0}$ & $z_{1}$ & $z_{2}$ & $z_{0}$ & $z_{1}$ & $z_{2}$ \\
\hline Ability Quartile 1: & 0.87 & 0.11 & 0.02 & 0.88 & 0.11 & 0. & 0.81 & 0.19 & 0.00 \\
\hline Ability Quartile 2: & 0.72 & 0.21 & $0 .($ & 0.76 & 0.21 & 0.03 & 0.75 & 0.24 & 0.01 \\
\hline Ability Quartile 3: & 0.53 & 0.31 & 0.16 & 0.55 & 0.29 & 0.16 & 0.60 & 0.29 & 0.11 \\
\hline Ability Quartile 4: & 0.24 & 0.27 & 0.49 & 0.23 & 0.28 & 0.49 & 0.30 & 0.24 & 0.46 \\
\hline
\end{tabular}

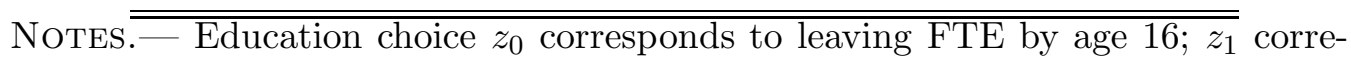
sponds to leaving FTE at age 17 or $18 ; z_{2}$ corresponds to leaving FTE at age 19 or above. The table reports the choices observed in the NCDS data and the simulated data for two alternative models. In the "disappointment aversion model" $\psi=0.62$ and $\gamma=1$. In the "risk aversion model" $\psi=0$ and $\gamma=3.89$. 